Instituto de Estudos Sócio-Ambientais

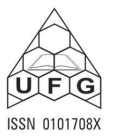

BOLETIM GOIANO DE GEOGRAFIA

v. 26, n. 1, jan./jun. 2006

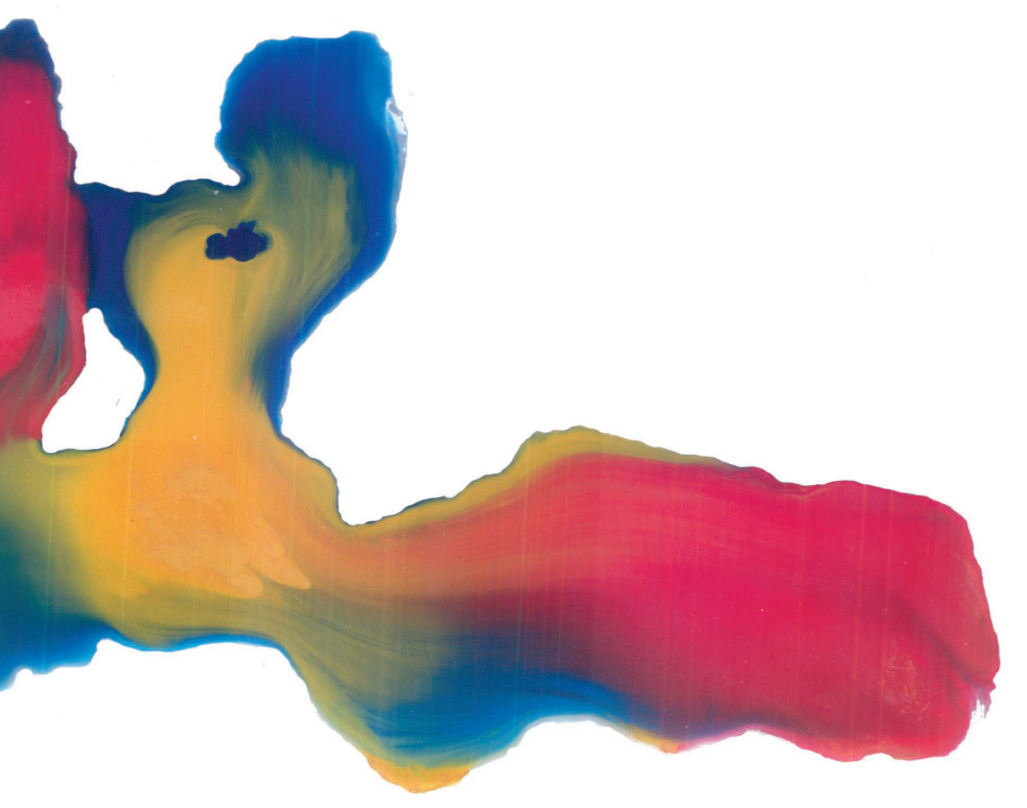

$\infty$
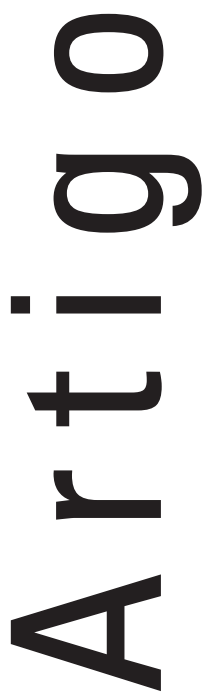


\title{
GOIÂNIA - DA UTOPIA À CONSTRUÇÃO DO LUGAR
}

\author{
GOIÂNIA - FROM UTOPIA TO THE CONSTRUCTION OF PLACE
}

\author{
Aluízio Antunes Barreira - IESA/UFG \\ aluisio.barreira@uol.com.br \\ João Batista de Deus - UFG \\ deus@iesa.ufg.br
}

\begin{abstract}
Resumo
Esse artigo tem como objetivo contribuir para a discussão do planejamento urbano, abordando a construção de Goiânia, cidade implantada no início da década de 1930, com um moderno plano urbanístico, que foi sendo subvertido ao longo da sua implantação e, principalmente, nas décadas posteriores. 0 artigo mostra como ocorreram essas mudanças e as conseqüências ambientais e urbanísticas para a cidade e seus moradores, assim como os atores principais das mudanças.
\end{abstract}

Palavras-chave: desenvolvimento regional, planejamento urbano, cidade, geografia urbana.

\begin{abstract}
This article aims to contribute to the discussion on urban planning. It is based on the construction of Goiania, a city implemented in the early 30's with a modern urban plan which, throughout the decades that followed, started to subvert as it was implemented. The article shows how these changes occurred as well as the environmental and urbanistic consequences to the city and its residents, and the key players in these changes.
\end{abstract}

Key-words: regional development, urban planning, city, urban geography. 


\section{Introdução}

A cidade é produzida ao longo de sua trajetória e ao ser analisada em determinado momento, o fazemos em relação ao espaço e ao tempo. As cidades sofrem mudanças e alterações através da multiplicidade de fenômenos que promovem transformações em situações urbanas que se apresentavam como definitivas. As modificações que atuam em muitas forças acabam por incidir nas cidades e podem ser de ordem política e econômica, entre outras. Uma cidade pode mudar por sua riqueza econômica que determina transformações no modo de vida ou sofrer mudanças por efeitos de guerras ou catástrofes. As transformações podem ser explicadas por medidas de planos da administração local que são realizados a partir de propostas de empreendedores que atuam sobre o aspecto espacial da cidade. Essas considerações implicam em admitir que existe um caráter coletivo no fato urbano.

A cidade se constrói na sua totalidade, isto significa que todos os seus componentes fazem parte da constituição de um fato. A cidade resulta do progresso da razão humana. Isto é, a cidade e qualquer fato urbano são por natureza coletiva. A forma da cidade é sempre a forma de um tempo da cidade. No decorrer da existência de vida das pessoas a cidade muda de fisionomia. Ao mesmo tempo em que se observa a forma na qual o urbano se estabelece, a cidade como agrupamento, pode ser explicada com base naquelas funções que os usuários queriam exercer. O estudo da morfologia passa a ser considerado um estudo que prioriza a função, pois quando se estabelece o conceito de função, surge imediatamente a possibilidade de uma classificação bem determinada, a exemplo de cidade comercial, cidade cultural, cidade industrial e outras (Rossi, 2001).

Ao projetar a cidade de Goiânia, planejada como cidade administrativa para ser a sede do governo de Goiás, em sua época, o grupo dirigente estabeleceu o número de cinqüenta mil habitantes. Desde o princípio da cidade teve uma convergência de habitantes e de valores de aspecto regional como pólo de desenvolvimento. Assim, passou a receber os diversos vetores de consolidação urbana e ao mesmo tempo em que as atividades administrativas propostas inicialmente cresciam e a ação do estado se consolidava em suas especificidades, como educação, cultura, saúde, segurança, fomento, fiscal, capacitação, entre outros, e fez com que o crescimento acelerado fosse uma condição precípua para a expansão urbana. Estes são aspectos considerados nessa reflexão. 


\section{A integração regional e a modernização do sertão}

Goiânia, Capital do Estado de Goiás, cidade de concepção recente, surgiu na primeira metade do Século XX como elemento de integração e desenvolvimento para o Estado de Goiás. Situada distante do litoral brasileiro, onde sempre predominou as grandes cidades e capitais da maioria de estados do país, o Estado de Goiás, apesar do relacionamento próximo com o Centro Sul brasileiro, ficava ausente aos aspectos políticos e movimentos econômicos nos qual o país participava.

As relações comerciais e culturais do Estado de Goiás foram ao longo do tempo predominantemente realizadas com os estados de Minas Gerais, São Paulo e Rio de Janeiro, onde abrigava a capital federal. O relacionamento maior com o Centro-Sul do país, devido à origem de penetração do território goiano e por ser a província de Goiás anteriormente pertencente à de São Paulo. A importância do aspecto físico da comunicação que podia ser feito por estrada, interligação fluvial e por situação geográfica dos estados relacionados.

Dessa forma a atividade econômica desenvolvida em função de produtos agropecuários e minerais produzidos pelo Estado, bem como a aquisição de bens manufaturados provenientes dos estados do Centro Sul, mais desenvolvidos tecnologicamente foi o elemento de ligação ao longo da história.

A relação de comércio era vantajosa para os estados do Centro Sul que cotavam preços de produtos de Goiás de acordo com a demanda. Quando havia oferta maior o preço caia e os produtos adquiridos pelo Estado sempre tinham preços que não diminuíam e às vezes os preços chegavam com sobretaxas, que acabavam por influenciar no resultado das operações realizadas.

No decorrer do tempo, com a implantação de uma infra-estrutura de transportes e a gradativa redução de barreiras aduaneiras interestaduais (1932), as relações comerciais com o Centro Sul estreitaram-se, especializando-se ainda mais na produção de bens primários para aquele mercado (Borges, 2000). A partir daí a expansão das atividades oferece uma articulação procurando aumentar a produção, mas ao especializar cada vez mais a atividade agrária e ampliar a inserção da economia na divisão inter-regional do trabalho, o Estado tornava-se um significativo espaço econômico cada vez mais articulado ao processo de reprodução ampliada do capital. 
O crescimento do Estado era lento e a construção da nova capital (1933-1942) provocou um surto migratório - composto em sua maioria por mineiros - para a Zona do Mato Grosso de Goiás (messoregião do Centro Goiano), deslocamento que foi facilitado pela ferrovia e pela expansão das estradas de rodagem, embora estas últimas fossem reconhecidamente precárias (IPEA, 2001).

As mudanças econômicas e políticas que ocorreram no Estado de Goiás, com o projeto e a edificação da nova capital foi um marco de aglutinação em investimentos que trouxe avanços significativos. Para o país, o Oeste representava, na visão oficial, um mundo em perspectiva. Era uma realidade geográfica a ser incorporada no quadro da civilização moderna (BoRGES, 2000).

Os anos que se seguem a Revolução de 1930 terão, portanto, enorme significado na história recente do Brasil e, em particular, na do Centro Oeste. De um lado, pelos efeitos dinamizadores do novo modelo econômico, presidido pela indústria, que estimulava a demanda por alimentos e criava maiores vínculos com as áreas de produção agropecuária. Com o interesse voltado para o consumo a região passa a ser vista com maior atenção, inclusive pela oferta de terras devolutas que atraia colonos do Centro Sul para o Centro Oeste. O período de 1930 a 1945 foi marcado por uma política deliberada do governo federal de ocupação das fronteiras, de preenchimento de vazios, conhecida como 'Marcha para o Oeste', em particular em Goiás, tratou-se de uma ocupação desordenada e predatória, realizada por contingente de trabalhadores expulsos de seu local de origem, desprovidos de recursos e munidos apenas de rudimentar tecnologia (IPEA, 2001).

A criação da nova capital representou a consolidação de uma idéia recorrente no imaginário do povo goiano, para que houvesse desenvolvimento, entre outros elementos, era a importância de fazer a mudança da sede do governo para um local que melhor atendesse de forma mais abrangente todo o território goiano. O sonho da transferência da capital goiana não era novo, pois a idéia de mudança era antiga e foi lançada pela primeira vez pelo marechal de campo Miguel Lino de Morais, $2^{\circ}$ governador de Goiás no império (Monteiro, 1938).

No início do Século XX o ideário da mudança teve avanços e fortaleceu-se nas ações políticas que demonstravam o aprimoramento dos elementos fundamentais para a realização tão esperada mudança. Com o surgimento da liderança política de Pedro Ludovico no Sudoeste do Estado e a ruptura 
política que ocorreu com a Revolução de 1930, surgiu um campo propício para efetivação concreta da idéia.

A economia de Goiás começou a sofrer transformações acentuadas com a chegada da estrada de ferro, na região Sul do Estado, o que possibilitou novas alternativas econômicas e contribuiu com o surgimento de atividades como: as charqueadas, as fábricas de aproveitamento de produtos agropecuários e a ampliação das atividades de comércio em geral.

A produção agrícola do Estado de Goiás se transformou devido ao processo de modernização ocorrido na época, tornando-se em 1920 o quarto maior produtor nacional de arroz. A modernização da economia agrária iniciada no Sul do Estado se explica pelo ajustamento da economia regional a partir das primeiras décadas do século ao processo de produção capitalista em expansão no país, assim o Estado de Goiás abre grande perspectiva que não havia sido obtida em períodos anteriores (BORGES, 1990).

Para a integração do Estado, deveria haver a mudança do local da capital histórica, que era Vila Boa de Goiás. Com essa medida, entendiam os goianos que a partir desta decisão das forças existentes seriam desencadeadas transformações que o Estado necessitava para atender as demandas acentuadas existentes.

A sede administrativa dentro do território goiano, pela localização geográfica não atendia as demais localidades com presteza, dada a fragilidade da comunicação disponível à época. As estradas não se adequavam à expectativa gerada por veículos automotores; a interligação com o Centro Sul e a distribuição dentro do Estado era inadequada, necessitando de uma postura política e investimentos para atender as cidades existentes. Assim o grande argumento a favor da mudança foi negar as condições à cidade de ser capital, e a base da crítica foi dada pelo que se chamou de argumento sanitário seguiu elencando itens desfavoráveis a Vila Boa, como o sítio, o clima, o abastecimento de água, rede de esgotos, habitações (CAmpos, 2002). Dessa forma, dentro de parâmetros urbanísticos de referência utilizados à época, não se justificava investimento maciço que deveria ser implantado na capital antiga ao custo muito superior do que iniciar um novo processo de ocupação urbana.

O aspecto de salubridade, elemento importante no apelo à mudança, era argumento no qual a localização da capital à época, tinha obstáculos enormes para serem superados para atendem satisfatoriamente a população residente no núcleo urbano. Esse período de mudança fez par 
com os anos 1930, marco na vida nacional com transformações profundas, como o êxodo rural, a industrialização do Centro Sul, a Marcha para o Oeste e a construção da nova Capital do Estado de Goiás. O movimento de interiorização do país (sinalizado pelo avanço de ferrovias e rodovias), criação de frentes de trabalho em agricultura e pecuária, também foram importantes.

A Revolução de 1930 trouxe novos dirigentes e, no Estado de Goiás, o então interventor federal Pedro Ludovico Teixeira, médico, político, intelectual e autêntico interprete dos interesses de grupos políticos que pretendiam transformar Goiás em um pólo de desenvolvimento e progresso. O dirigente assumiu a responsabilidade de construir uma nova cidade administrativa, mesmo com resistência dos habitantes e políticos da cidade de Vila Boa de Goiás (Manso, 2000).

Ao ser apresentada a proposta de uma nova cidade, por intermédio de empreendimento concebido com uma visão universalista, reacendeu as esperanças daqueles que sempre buscaram melhores condições em todos os aspectos para os habitantes do território goiano. A iniciativa para a viabilização da nova Capital começou a materializar-se com a publicação do Decreto Lei $\mathrm{n}^{\circ} 2.737$ de 20 de dezembro de 1932, no qual o interventor federal nomeou a comissão para escolha do local ${ }^{1}$.

A maturação do processo teve encaminhamento dentro de uma comissão com técnicos envolvidos com políticas urbanas, e participação de membros da sociedade que integraram a comissão de escolha do sitio. Segundo Manso (2001, p. 67): “...critérios básicos foram fixados de início como medida para escolha: o local, além de ser próximo da estrada de ferro, deveria dispor de água abundante de bom clima e de topografia adequada". Com diretrizes para análise das áreas seguiram-se parâmetros pré-estabelecidos, sobressaindo-se elementos geográficos, como condições topográficas, hidrológicas e climatéricas, que pudessem atender com excelência a nova cidade.

Mesmo com os estudos realizados pela comissão criada, o interventor federal solicitou parecer de Armando Augusto de Godoy, urbanista que já havia realizado diversos trabalhos na Capital Federal, que fez detalhado parecer explicando e justificando de maneira isenta porque a escolha e qual o sítio mais adequado para a construção de uma nova cidade. Houve também um componente político que foi a determinação, mesmo sem maiores recursos financeiros de enfrentar o desafio de construir uma cidade para cinqüenta mil habitantes. 
Esta capital planejada surgiu como cidade de fronteira, marco referencial de alterações no Estado de Goiás e na Região Centro Oeste a partir de seu início. Segundo Silva (2000, p. 133): "A construção da nova Capital de Goiás, pode ser entendida como um capítulo da construção identitária regional pela via da adesão à modernidade”. Neste processo de escolha, procurou-se de uma forma contemporânea de cidade que superasse os aspectos históricos que fizeram como relíquia de um passado, o modelo urbano diferente do período colonial.

Como cidade planejada, a primeira do Século XX no Brasil, houve a preocupação não apenas com o lugar, mas também com toda a região. Segundo Silva (2000, p. 157): "Na elaboração do plano de Goiânia, Atílio baseia-se na concepção de planejamento regional, confirmando a importância do conhecimento da história e da formação da Região para que nela possa atuar”. A preocupação em estabelecer uma proposta do urbano e também a compreensão da ocupação de um espaço regional que posteriormente vai proporcionar sustentação para uma cidade de convergência de interesses mais amplos. Constituiu-se, desde então, como elemento de penetração do território, se contrapôs a capital anterior, e passou a apresentar-se em ponto de convergência de interesses e investimentos e consolidou-se de forma rápida e concreta. Demonstrou que era possível, em pleno sertão, deslocada dos centros de desenvolvimento do país à época, ocorrer um fato urbano que passou a ser pólo de integração nacional.

Esta cidade administrativa, planejada, surgiu como cidade de fronteira. Segundo Silva (2000, p. 131): "a experiência histórica que se liga à construção de Goiânia é a abertura, conquista e ocupação de novos territórios”. De acordo com Moysés (2004, p. 1): "Goiânia foi viabilizada no momento em que o país desempenhava um grande esforço de interiorização de um processo de ocupação econômica em moldes mais modernos".

A posição da cidade, segundo Gonçalves (2002, p. 27): “Capital do Sertão”, demonstra que este aspecto único em cidades pelo país e a única planejada até então no Século XX e que de forma bastante explícita onde o atraso e a modernidade se relacionavam criando um urbano diferenciado de inúmeras fronteiras urbanas que iam surgindo no país.

Dada as circunstâncias de um Estado fora do eixo econômico central do país, e com recursos limitados para realizar uma obra urbanística de grande porte, houve a determinação de iniciar e de fazer cumprir o plano diretor proposto. A importância de uma cidade planejada, inclusive com um plano diretor e com legislação de uso do solo, teve repercussão de grande 
importância para a ocupação do lugar. O sítio do traçado original da cidade teve ocupação organizada com perfil moderno e de maneira diferenciada, então vista em outras cidades do Estado.

A economia urbana surgiu com instalação do canteiro para as obras que, incrementadas pela e indústria da construção civil e atividades envolvidas no processo, deram sustentação ao inicio da Nova Capital. Posteriormente esta base se reforçou com a consolidação da cidade, a remuneração do funcionalismo público e prestadores de serviços. Quando da implantação da cidade de Goiânia, segundo Maciel (2003, p. 1): “O Estado de Goiás tinha um baixo índice de urbanização e pequena taxa de população e a localização de moradores era de cerca de 80\% na zona rural".

Nesta condição, as atividades comerciais eram de porte reduzido e a produção no campo era de subsistência e baseadas em unidade de produção dentro do Estado. As dificuldades e incertezas das relações comerciais com outras regiões brasileiras formavam o quadro de baixa arrecadação fiscal e o Estado com um dos menores orçamentos entre os estados da federação, naquele momento. A população tinha modo de vida rústico, situando-se em lugares isolados sem recursos financeiros e sem um intercâmbio cultural e educacional com o restante do país.

Para a escolha do local de instalação da nova cidade houve realmente uma convergência de ações que caracterizavam um estudo eminentemente técnico e que, analisado nos dias de hoje, mostra que a escolha foi a mais adequada em todos os aspectos estabelecidos previamente para a escolha do sítio. Entre os aspectos do parecer de Augusto Godoy para referendar a escolha do sítio da nova cidade, considerou-se aspectos fundamentais para instalação e crescimento. As condições favoráveis a que ele se referia diziam respeito: a) à curta distância entre a área escolhida e a linha férrea; b) à localização da área no centro da zona mais próspera e habitada do estado; c) ao clima adoçado pelo grau hidrométrico; d) à vizinhança de matas que constituem requisitos preciosos nas proximidades de um centro urbano; e) as condições topográficas com suaves ondulações, que favorecem o traçado moderno; f) às condições hidrológicas, condição fundamental para que a sede possa ser abastecida com quantidade suficiente de água; g) à fertilidade do terreno; h) à possibilidade de oferta de energia elétrica de que o desenvolvimento e a prosperidade do centro urbano dependem enormemente: e i) aos materiais de construção que mais se afiguram na região. Entre estas, várias circunstâncias influenciaram a comissão que optou por Campinas (MANSO, 2001). 
O comércio, a construção civil, investimentos e prestação de serviços voltados para a criação de uma cidade proporcionaram a consolidação de uma estrutura que gerou ao longo do tempo outras demandas além do canteiro de obras. A expansão de atividades econômicas extrapolou o município e trouxe o fortalecimento para região.

A nova cidade se estabeleceu assim como fato em si mesmo (o lugar construído) e, ao mesmo tempo, como um dos elementos formadores da região. O espaço geográfico é entendido como o local de reprodução social, de produção em conjunto articulado com a cidade e sua região. A produção local de materiais básicos de construção civil resultou na formação de um mercado de trabalho relevante para a época. Os produtos tinham que ser extraídos ou confeccionados (areia, madeira, pedra, tijolo, telha, entre outros), em locais próprios e levados para o canteiro de obras. Inicialmente, eram usados animais de tração e, rapidamente os veículos motorizados passaram a trabalhar em tempo contínuo para atender à demanda. As estradas de rodagem foram surgindo e se aprimorando, pois a movimentação era feita pelos construtores e empreendedores e com alguma ajuda oficial.

A estrada de ferro também contribuiu, pois a "ponta" da ferrovia havia chegado a Anápolis em 1935, ficando a 50 km de Goiânia. O processo de relacionamento entre Goiânia e outras cidades cresceu de forma contínua, apesar no início incipiente e, ao longo do tempo superou barreiras culturais e geográficas. Segundo Borges (2000, p. 250): "a transferência da Capital para as proximidades do centro mais dinâmico da economia regional atendia aos interesses das novas forças econômicas e políticas emergentes e reforça o mito da conquista do Oeste, bem como a da criação do "Novo Brasil". É possível observar a tendência do crescimento das atividades econômicas, conforme dados da Tabela 1 de Receitas Arrecadas do Estado, e sua reação com a nova capital.

Com os valores em moeda da época nota-se que a influência da nova cidade na economia do Estado realmente trouxe um aporte de recursos significativos com crescimento importante para o desenvolvimento regional. Goiânia surgiu como cidade que passou a ser um ponto de relações comerciais, integrando uma rede de cidades no país. Conforme Corrêa (1997, p. 17)

a emergência de uma rede hierarquizada e integrada nacionalmente de centros de distribuição varejistas e de serviços, isto é, localidades centrais, se verifica com o capitalismo, com o domínio de um modo de produção onde o capital penetra na esfera de produção. 
Tabela 1: Receitas arrecadadas no Estado de Goiás

\begin{tabular}{|l|c|}
\hline \multicolumn{1}{|c|}{ Ano } & C\$ \\
\hline 1930 & $4.961 .020,00$ \\
\hline $1933^{1}$ & $6.727 .489,00$ \\
\hline $1937^{2}$ & $14.174 .700,00$ \\
\hline $1942^{3}$ & $29.293 .313,80$ \\
\hline 1958 & $1.362 .974 .000,00$ \\
\hline
\end{tabular}

Observações: ${ }^{1}$ Ano da fundação de Goiânia. ${ }^{2}$ Mudança definitiva. ${ }^{3}$ Batismo cultural de Goiânia.

Fonte: Sabino Junior (1960, p. 47).

A cidade com funções de governo possui uma compreensão diferente de cidades referenciais de lugar. As capitais se erguem para o capital são racionalizações administrativas e burocráticas do Estado que se compõe na lógica do capitalismo. São espaços que permitem organizar o jogo político, são palcos do aplauso oportunista de plantão, mas também perspectivas que se abrem rumo à modernidade (CHAUl, 2000). Mesmo no início da cidade, o novo proporcionou conteúdo de técnicas que introduziram a modernidade de aspecto urbano. Criou-se um movimento formado pelo conjunto de realizações e materiais que foram sendo disponibilizados. Segundo Ferrara (1999, p. 201): "além das explicações socioeconômicas do urbano, estão as imagens da cidade que assinalam uma robusta realização humana, uma forma distinta de civilização." A nova cidade trouxe diferenciados elementos construtivos desconhecidos em uma região de interior, de sertão, do cerrado.

As transformações introduzidas, junto com técnicas construtivas diferentes resultaram no cuidado com o acabamento de prédios públicos e residências para funcionários, dentre outras modernidades. Os novos elementos foram indicativos para que a população se preocupasse mais na edificação de suas residências, criando um universo novo e revolucionando conceitos. Trabalhadores do local tiveram de se adequar a novos padrões construtivos delimitados pelas exigências do momento.

As transformações construtivas de estilo visual diferentes, entre outros, como Art Decò, Eclética, Moderna, Modernista foram introduzidas em várias edificações da zona central da cidade Goiânia. Com projetos arquitetônicos e técnicas que incrementaram outros modos construtivos foi possível realizar um contraponto às edificações tradicionais que eram feitas na região. 
Na Figura 1, nota-se as primeiras construções da cidade, como Grande Hotel, na Avenida Goiás e um traçado urbano que surgiu no meio do cerrado.

Figura 1: Goiânia vista do alto do Palácio das Esmeraldas, 1937

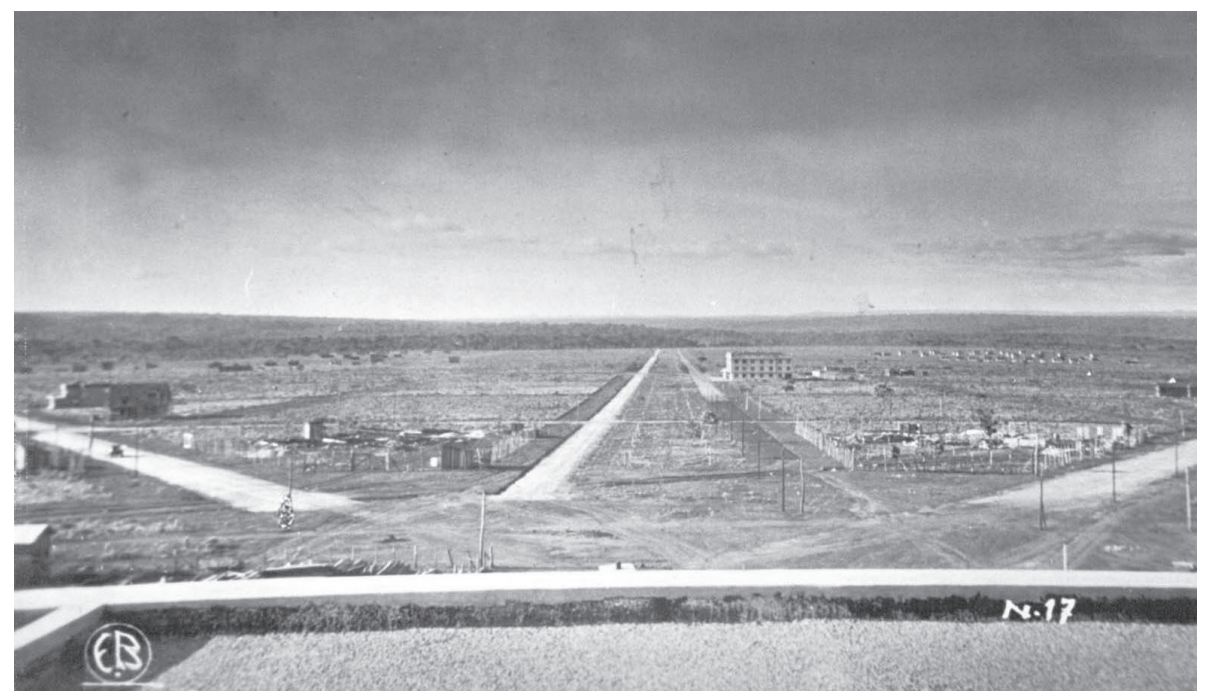

Fonte: Arquivo S.M.C./ Seplan. Autor: Eduardo Bilengian.

Como podemos observar, estas construções eram feitas a partir de cópias de casas coloniais e adaptadas às situações locais, conforme mostra a Figura 2. As cidades coloniais goianas tinham formas construtivas tradicionais, com as casas emendadas entre si e o acesso da rua diretamente aos ambientes internos.

Figura 2: Casas estilo Colonial
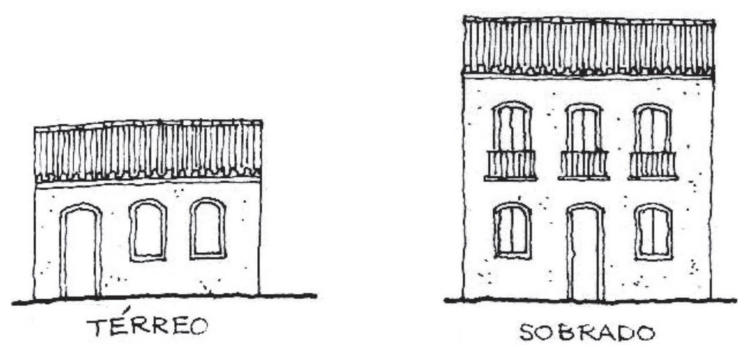

Fonte: Reis Filho (1970). 
A nova cidade foi construída com o maior cuidado e atenção possível por um governo que não mediu esforços em associar a imagem da cidade à modernidade (GonçALVES, 2002). O elemento dito "moderno" à época e atualmente entendido como "modernidade" fazia um contraponto a cultura urbana de época. Não apenas na tipologia das edificações, mas, sobretudo na forma de uso da habitação. Eram construídas no estado de características rústicas, tanto urbanas como rurais, tendo seus cômodos com funções diferentes dos usos do presente. Eram edificações que não possuíam forros (apenas os mais abastados possuíam forro de madeira ou em tecidos), em cômodos mais íntimos para evitar insetos, répteis e animais. Os cômodos de banho não possuíam encanamentos ou tubulações de água e esgoto, utilizando bacias ou banheiras que eram abastecidas manualmente por empregados ou usuários. O cômodo sanitário funcionava distante da edificação principal, com fossa negra, sem iluminação ou ventilação, ao relento no sol e chuva.

Já na nova cidade, foi exigido que as casas tivessem afastamentos dentro do seu terreno, e afastamento frontal, sem muros altos, prestigiando a formação de jardins em frente das casas. O aspecto urbanístico foi importante para criar dos visitantes uma imagem de modernidade, que propagou rapidamente. A organização de cidade valorizou elementos arquitetônicos e proporcionou conceitos diferentes com grandes espaços públicos e avenidas largas. Em toda obra a ser iniciada, havia funcionários para marcar divisas, afastamentos, de acordo com o memorial descritivo do bairro, criando jardins em frentes as casas. As casas construídas pelo governo para abrigar funcionários tiveram projetos diferenciados, com um e dois pavimentos. Existem ainda algumas construções da época na área central da cidade.

A arquitetura abandonou o estilo colonial e o barroco usual. Surgiram novos projetos diferenciados baseados em Art Déco em voga na Europa e nos Estados Unidos. Os primeiros exemplos do estilo modernista começaram a ocupar os lotes do centro da cidade.

O desenvolvimento regional, desde o início da cidade foi suscitado, pois o urbano representava o novo e o entorno da cidade ainda era o "sertão". Era necessário prosseguir idéias e mecanismos que fizessem a articulação entre segmentos urbano e rural no sentido de harmonizar o crescimento para os goianos. Segundo Álvares (1942, p. 147): “a preocupação com o efeito regional da implantação de Goiânia suscitou preocupação quanto ao suporte de ações basilares para a sustentação econômica...”. 


\section{As mudanças no projeto original e ocupação não planejada}

O urbano se formou muito rapidamente e trouxe efeitos diversos. Por um lado, adensou vazios na cidade em construção, movimentou a economia, e por outro criou áreas de ocupações irregulares em fundos de vale e áreas institucionais. Para Bernardes (2000, p. 173): “A ocupação do espaço não planejado ocorre concomitante à construção dos primeiros edifícios da cidade". E segue explicando: "não foi reservado um espaço no plano da cidade para aqueles que seriam os seus primeiros moradores, justamente os que vieram trabalhar de Goiânia".

Na implantação da cidade, os trabalhadores tinham que residir fora da área do plano original de Goiânia, como os Setores Central, Norte, Sul e Oeste. Atraídos pela notícia da construção da cidade, estes trabalhadores viajavam por meses, dias seguidos, geralmente parando em outras localidades, às vezes utilizando seus próprios pés para chegar a Goiânia. Sem uma organização para atender aos que chegavam, sem recursos para se instalar, sem moradias adequadas para abrigar a família, sem recursos para morar em Campinas $^{2}$ como fazia a maioria dos que chegavam e nem para comprar um lote no Bairro Popular, esses trabalhadores se alojaram às margens do Córrego Botafogo, nos espaços vazios, fundando as primeiras invasões nas terras públicas de Goiânia (BERNARDEs, 2000).

Na época não houve empenho em preservar áreas valiosas para o meio ambiente da cidade, gerando o impacto que pode ser constatado na redução do volume de áreas verdes e arborização de vias. Nem mesmo as nascentes e cursos d'água que foram cortados e ocupados por obras e que poderiam ser edificadas em outros locais enquanto havia áreas disponíveis, foram preservadas.

Com o passar do tempo a realidade do urbano é apresentada como elemento de união do habitante com a cidade, apesar de diversas situações de dificuldades, principalmente com o grande adensamento inicial para os padrões da época, pelas grandes distâncias com centros fornecedores de insumos e serviços, mão-de-obra especializada escassa e infra-estrutura implantada por etapas, o que dificultava o uso completo da cidade, com falta de energia e interrupções em abastecimento de água.

Houve diferenças entre a proposta inicial de planejamento urbano e a efetiva implantação da cidade. A proposta urbanística foi estabelecida de maneira a produzir uma ocupação observando as condições físicas do sítio escolhido. Um projeto que abrigasse uma população estimada em cinqüenta mil habitantes. E na medida do crescimento da cidade deveriam ser constru- 
ídas Cidades Satélites, fora do cinturão verde, formado pelos vales dos Córregos Botafogo e Buritis. As interferências ao projeto inicial foram feitas sem o cuidado de preservar o sítio existente. Por interesses outros, aqueles que assumiram tal responsabilidade não dispunham de conhecimentos técnicos suficientes para saber que a agressão ao meio ambiente de forma sistemática acabaria por extinguir o frágil equilíbrio existente. Com o passar do tempo desapareceram vegetação e cursos d'água.

O controle pelo Estado das construções da cidade, em 1947, passou para o domínio do Município. Na década de 1950 houve uma pressão de proprietários de glebas para o parcelamento de lotes, quando então foram aprovados 130 loteamentos, contribuindo assim para a descaracterização da proposta inicial da cidade (GoIÂNIA, 2003).

Assim, houve ocupação fora dos padrões definidos pelo projeto da cidade e criação de mecanismos legais para consolidar estas situações. Um exemplo deste descaso foi com as nascentes do córrego Buritis que sofreu intervenções: primeiro a construção de um abrigo para idosos junto à passagem na Avenida Assis Chateaubriand no Setor Oeste, que depois foi demolido para construir o Tribunal de Justiça e o Fórum da cidade, com redução significativa do Parque dos Buritis.

Outras nascentes do mesmo córrego sofreram intervenções, inclusive com doação de áreas para várias entidades no Setor Sul, onde havia vegetação expressiva, no início de formação do Córrego Buritis. Hoje [2006] o Córrego Buritis está canalizado, no Córrego Capim Puba, que no início da cidade tinha a maior mata ciliar do sítio de Goiânia, resta poucas árvores na nascente junto ao Lago das Rosas.

Os espaços livres que deveriam ser deixados para o convívio da população foram sendo reduzidos por ocupações indevidas. Isto não deveria acontecer, pois a cidade não tem apenas o papel de produzir e circular riqueza. Tem também a função de proporcionar prazer aos seus habitantes. Mesmo sendo planejados os espaços livres para atividades de lazer da população ao longo do tempo houve um conjunto de ações que acabaram por facilitar a alteração da destinação original dos bens públicos por instituições que poderiam ocupar locais diferentes. Verifica-se aí uma falta de compromisso com a cidade e falta de determinismo de algumas autoridades que não foram firmes o suficiente para não permitir a quebra de harmonia da cidade que foi pensada e planejada como um todo. Aconteceu com o Parque dos Buritis que no início tinha uma área de 40 ha, sendo reduzida nos dias de hoje para apenas 12 Ha. (MARTINS JúNIOR, 1996). 
Mapa 1: $\quad$ Alteração no parque Buritis

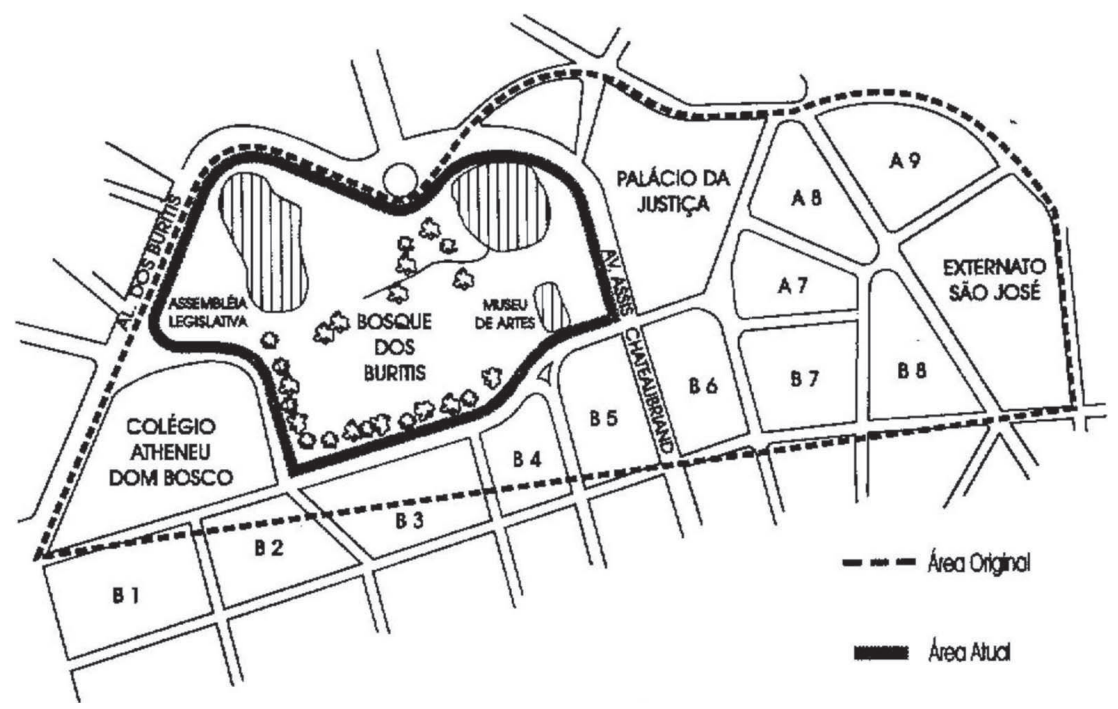

Fonte: (MARTINS, Junior, 1996).

No Mapa 1, ficam caracterizadas as mudanças no projeto de origem e a situação atual do Bosque dos Buritis. Onde foi doadas áreas para os colégios Ateneu Dom Bosco, Colégio São José, sede do Tribunal de Justiça do Estado, Fórum de Goiânia, Assembléia Legislativa e várias quadras de lotes no lado do Setor Oeste.

Elementos de condicionantes estruturais acabaram por impor situações de grande impacto à época. A preponderância da economia de subsistência em grande parte do Estado de Goiás impõe ao governo ações no sentido de alterar-lhe a dinâmica, a partir da década de 1950 e é a força do capital que se impõe, forçando o Estado a assumir, em forma de lei as transgressões ao planejamento que, na prática, já acontecia pontualmente (BERNARDES, 2000).

Outro exemplo claro foi à ocupação de praças de lazer da população, por terminais de transporte coletivo, que poderiam ocupar outros terrenos e a população ficou com seus espaços livres comprometidos, como Praça da Bíblia, Praça Izidória, Praça A, entre outras, sem condições de uso para as populações adjacentes. Com locais mal resolvidos, "sobram” áreas que são disputadas por camelôs e pessoas sem local de estadia.

Na Figura 4, é possível identificar matas e vegetação ciliar junto ao Córrego Capim Puba, ao longo dos cursos d’água, na época da construção 
da cidade. O processo de urbanização acelerada da cidade preencheu áreas que deveriam ser reserva para futuras ocupações, desde o início das obras com o escritório da firma construtora que transformou na invasão do Botafogo, como o Setor Bela Vista, objeto deste estudo, Setor Pedro Ludovico, Jardim das Esmeraldas, Setor Universitário, Setor Vila Nova, entre outros. Sem implantação mínima de infra-estrutura necessária. Dentro de aspectos urbanísticos naturais de crescimento, o acentuado e acelerado modelo de ocupação causou desequilíbrios de ordem estrutural na cidade. Na urgência de fornecer áreas parceladas, não havia a implantação de infra-estrutura nos bairros fora do plano original. As ligações viárias com a Zona Central eram feitas de maneira precária e prevaleceram, mesmo sem ser as mais adequadas, como o acesso à Vila Nova, extensão da Avenida Araguaia, no meio do Bosque do Botafogo.

Nestas condições, o abastecimento de água teve que ser feito por meio de cisternas perfuradas individualmente em cada lote, nos anos 50, sendo que e no próprio bairro havia reservatório e tratamento de água. Como exemplo, o setor Sul onde havia um reservatório de água acima de Rua 94, que não possuía rede de distribuição para o abastecimento local.

A ocupação urbana que ocorreu nas décadas de 1950 e 1960, trouxe um crescimento de três vezes o volume de população, ou seja, em uma década, a população passou de 53.389 para 153.505 habitantes (dados do Censo IBGE), ocasionando situações que tiveram de ser assimiladas de forma precária. Conforme a Tabela 2, o parcelamento urbano teve seu ápice na década de 1950.

Tabela 2: Goiânia - Evolução do parcelamento (1930-2001)

\begin{tabular}{|l|c|c|}
\hline \multicolumn{1}{|c|}{ Período } & Parcelamento & Lotes \\
\hline Década 30 & 6 & 14.660 \\
\hline Década 40 & 2 & 4.356 \\
\hline Década 50 & 160 & 118.558 \\
\hline Década 60 & 30 & 30.024 \\
\hline Década 70 & 24 & 22.444 \\
\hline Década 80 & 34 & 25.811 \\
\hline Década 90/01 & 206 & 105.476 \\
\hline Subtotal & 462 & 321.329 \\
\hline Loteamentos não aprovados / irregulares & 62 & 19.177 \\
\hline Total & 523 & 340.506 \\
\hline
\end{tabular}

Fonte: SEPLAM - Prefeitura Municipal de Goiânia. 
O crescimento da cidade teve como conseqüência a alteração do zoneamento da área central da cidade, ampliando a zona para instalação de edificações comerciais. Ocuparam-se áreas que seriam prioritariamente residenciais. Campinas, cidade que deu suporte à implantação de Goiânia, posteriormente transformou-se em bairro da cidade, começou a receber lojas de autopeças, concentração de oficinas mecânicas de autos, atacadistas e serviços.

Nas décadas de 1940 e 1950, o bairro de Campinas abastecia Goiânia em muitas frentes de sua construção. Como exemplo, em termos de trabalhadores diversos, de mão-de-obra industrial, de fornecimento de produtos industrializados pelo fato de possuir diversas unidades industriais (marcenarias, carpintarias, pequenas forjas, olarias, cerâmicas, selarias, padarias etc.) e a população sabia onde encontrar os serviços (Gomes, 2005). Seus terrenos foram sendo transformados em edificações de moradia para comércio e serviços e algumas indústrias que resistiram ao crescimento urbano do bairro. Esta re-orientação no espaço intra-urbano prevaleceu mais por força do mercado imobiliário do que do aparato da legislação que sempre "buscou" o desenvolvimento.

Historicamente, os proprietários de empreendimentos imobiliários definiam suas ações a partir de uma escolha de local, e, em seguida procurava verificar a situação legal para a consolidação do empreendimento. Bairros como o Setor Oeste que estava mais próximo e com ligação com o Centro se transformou rapidamente em local de construção de edifícios com vários pavimentos. O Centro da cidade já havia passado por experiência da década de 60 da implantação de prédios sem garagens como os expressivos prédios do cruzamento das avenidas Goiás e Paranaíba, com muitos pavimentos. Assim foi construído um grande número de edifícios no Centro e descaracterizando o afastamento frontal de cinco metros nas casas que encantou a muitos visitantes no início da cidade.

Com a nova legislação que exigia a infra-estrutura completa e a construção de garagens para atender ao número de apartamentos, a ocupação de áreas fora do Centro teve aceitação maior, como nos setore Oeste e Bueno.

Mesmo assim a pressão dos loteadores nos anos 1970 fez surgir um zoneamento que permitiu ocupar áreas que deveriam ser mantidas com ocupação mínima proporcionalmente uma vez a área do terreno, como o caso das Alamedas das Rosas, não permitindo à distância a vista da área verde, onde foi criado um paredão de prédios. 
Recentemente, processo semelhante ocorreu no Setor Bueno que foi sendo ocupado, inclusive nas nascentes do Córrego Vaca Brava de densidade questionável, aprovados edifícios como "uso especial" para aumentar o gabarito, criando assim o mesmo efeito de obstruir a vista de um espaço público que pertence a todos os moradores da cidade.

\section{Considerações finais}

O que ficou na memória daqueles que fizeram a escolha por mudar suas vidas a partir da nova capital, traz como conotação básica o sentimento colocado como Neto (2005, p. 1):

...então a cidade de Goiânia, que por volta de 1953 tinha pouco mais de 50.000 habitantes, era para mim um lugar que, naquele tempo, alimentava meus sonhos, como, dentre outros, o de morar na capital.

Esta constatação era o sentido do pensamento de quem se transferia para a cidade que todos naquela época compreendiam que seria grande. Era uma conquista para um início de uma luta. Mais adiante Neto (2005, p. 1) escreve: "Mas eu continuei alimentando aquele sonho, porque um desejo danado tomou conta de mim: estudar na Escola Técnica”.

O sonho que transformou em realidade, mostrou que a cidade nova, com sua estrutura, foi um ponto de absorção de importantes segmentos que a buscaram por um ideal. Independente do fascínio que representava à época, esse novo aspecto urbano no Estado, onde as aspirações passaram a ser canalizadas, proporcionou um aparato organizacional próprio. Forçou a própria sociedade e instituições a promover ações mais dinâmicas para suporte de milhares de sonhos que continuamente se dirigiram para o mesmo local que era Goiânia.

Ao mesmo tempo o universo formal de consolidação da cidade, apesar de bairros e ocupações proletárias, a cidade acontecia nas áreas denominadas centrais, isto é, no sentido Norte Sul da estação ferroviária à Praça Cívica e no Sentido Leste Oeste do Córrego Botafogo até ao Lago das Rosas.

Esta perspectiva trazia o modo de ver a cidade à época. A visão do habitante observada pelo seu deslocamento, sem auxílio de veículos coletivos ou particulares, olhando a cidade de uma perspectiva real, mostra que o perímetro central de Goiânia sempre foi um universo imenso na compreensão das pessoas. Não havia linhas regulares de coletivos, a não ser para Campi- 
nas, o que deixava a população sem opções de transporte. Nos anos 1950 Goiânia era uma das cidades que mais possuíam bicicletas por habitantes. A população andava a pé em bairros com ruas sem pavimentação. Assim, a cidade para o pedestre sempre se apresentou com grande volume de edificações e de grandes extensões devido a dificuldade de locomoção.

Aqueles que vinham para atividade específica como estudar, trabalhar ou mesmo conhecer a cidade alimentava a ampliação do número de edificações em núcleos em determinados locais, como o setor Norte (chamado de Bairro Popular e hoje faz parte do Centro da cidade). Neste setor era comum a construção de "barracões" (edículas) nos fundos do terreno para abrigar parentes, estudantes e mesmo como cômodos de aluguel e ter renda extra. Havia a prática de abrigar parentes vindos interior, se hospedar nas casas dos conterrâneos que haviam chagado primeiro. Provocando o aumento da densidade populacional no bairro. De acordo com Wiederhecker (1998, p. 24):

...a cidade pode ser vista como o ápice da arquitetura sócio-espacial de uma sociedade; ela supõe formas de organizações superiores e expressa a síntese do que aquela produziu historicamente, a síntese da transformação da natureza pelo homem, um espaço-produto portanto.

Enfim, o processo de criação de uma cidade envolvia, além de questões políticas, técnicas, culturais e locais, a incorporação da idéia de ocupação do lugar, e ainda, no caso de Goiânia, meta política conduzida com afinco pelo Governo Central. A comunicação que movimentou grande contingente populacional que veio e ficou, criou um quadro socioeconômico que fez Goiânia transformar-se em um pólo de difusão econômico social, trazendo importantes alterações no perfil regional e, portanto, na construção dos lugares no espaço intra-urbano da nova capital.

\section{Notas}

1 Monteiro (1938, p. 32). art. $1^{0}$ - fica nomeada uma comissão composta dos srs. D. Emanuel Gomes de Oliveira; engenheiro João Argenta, urbanista; Dr. Colemar Natal e Silva, advogado; Cel. Antonio Pirineus de Sousa, oficial superior do exército; Dr. Laudelino Gomes de Almeida, chefe do Serviço Sanitário do Estado: Antonio Augusto de Santana e Gumercino Alves Ferreira, comerciante; e o engenheiro do Estado, para proceder aos estudos atinentes a adaptação ou escolha de local para nele ser edificada a nova cidade.

2 Cidade próxima ao local da construção da nova capital, que deu suporte à implantação de Goiânia, posteriormente transformou-se em bairro da cidade. 


\section{Referências}

ÁLVARES, Geraldo Teixeira. A luta na Epopéia de Goiânia: documentos históricos, técnicos e descritivos. Rio de Janeiro: Jornal do Brasil. 1942.

BERNARDES, Júlia Adão. Mudança técnica e espaço: uma proposta de investigação. In: CASTRO, Iná Elias de; GOMES, Paulo César da Costa. Explorações geográficas. Rio de Janeiro: Bertrand Brasil, 2002.

BORGES, Barsanufo Gomides. O despertar dos dormentes. Goiânia: Ed. UFG, 1990.

. Goiás nos quadros da economia nacional: 1930-1960. Goiânia: Ed. UFG, 2000.

CAMPOS, F. Itami. Mudança da capital: uma estratégia de poder. In: BOTELHO, Tarcísio. Goiânia cidade pensada. Goiânia: Ed. UFG, 2002.

CHAUL, Nasr Nagib Fayad. Caminhos de Goiás: da construção da decadência aos limites da modernidade. 2. ed. 1. reipr. Goiânia: Ed. UFG, 2002.

CORREAA, Roberto Lobato. Trajetórias geográficas. Rio de Janeiro: Bertrand Brasil, 1977.

FERRARA, Lucrecia D’Alessio. Olhar periférico. 2. ed. São Paulo. Edusp. 1999.

GOMES, Orieste. Entrevista. Goiânia em 03.05.2005.

GONÇALVES, Alexandre Ribeiro. Goiânia: uma modernidade possível. Brasília: Ministério da Integração Nacional/UFG, 2002.

IBGE. Goiânia. Rio de Janeiro: Ed. IBGE. 1942.

IPEA/IBGE. Caracterização e rendências das redes urbanas regionais: Norte, Nordeste e Centro Oeste. Brasília: IPEA, 2001.

MACIEL, Dulce Portilho. Estabelecimento do comércio "em grosso" na economia de Goiânia, cidade em formação (1933-1963). Texto. Rio de Janeiro: IPPUR-UFRJ, 2003

MANSO, Celina Fernandes Almeida. Goiânia: uma concepção urbana, moderna e conteporânea - um certo olhar. Goiânia: Ediçõa do Autor, 2001.

MONTEIRO, Ofélia Sócrates do Nascimento. Como nasceu Goiânia. São Paulo: Revista dos Tribunais, 1938.

MOYSES, A. Goiânia: metrópole não planejada. Goiânia: UCG, 2004.

NETO, Antônio Teixeira. Entrevista. Goiânia em 14.04.2005.

REIS FILHO, Nestor Goulart. Quadro da arquitetura no Brasil. São Paulo: Perspectiva, 1970.

ROSSI, Aldo. A arquitetura da cidade. Trad. Eduardo Brandão. 2. ed. São Paulo: Martins Fontes. 2001.

SABINO JUNIOR. Goiânia global. Goiânia: Oriente, 1980.

SEPLAN-GO. Anuário Estatístico do Estado de Goiás. Goiânia: SEPLAN-GO, 2003.

SILVA, Luiz Sérgio Duarte da. A construção de Brasília: modernidade e periferia. Goiânia: Ed. UFG, 1997. 
(Org.). História dos bairros de Goiânia. In: . Relações cidade-campo: fronteiras. Goiânia: Ed. UFG, 2000.

WIEDERECKER, Clyce Louise. Cidade, Promessa, Exclusão. O Césio-137 em Goiânia. Tese de Doutorado. São Paulo. USP. 1998.

ALUIZIO ANTUNES BARREIRA - Arquiteto, Mestre em Geografia pelo Instituto de Estudos Sócio-Ambientais da Universidade Federal de Goiás.

JOÃO BATISTA DE DEUS - Professor Adjunto e Diretor do IESA/UFG.

Recebido para a publicação em maio de 2006 Aceito para a publicação em junho de 2006 